\title{
Microscopic Findings Chronicity
}

National Cancer Institute

\section{Source}

National Cancer Institute. Microscopic Findings Chronicity. NCI Thesaurus. Code C123941.

A description or characterization of the duration of a microscopic finding. 